\title{
One-trial backward fear conditioning in rats as a function of US intensity
}

\author{
PAUL E. BURKHARDT \\ University of Wisconsin, Oshkosh, Wisconsin 54901
}

\begin{abstract}
In a one-trial backward conditioning procedure, four groups of seven rats each received a 4-sec white noise conditioned stimulus (CS) immediately following a 4-sec electric grid shock unconditioned stimulus (US). For different groups the US intensity was .5, 1.0, 1.6, or $2.0 \mathrm{~mA}$. A fifth group served as a sensitization control and received a single 4-sec, 2.0-mA US presentation, but no noise CS. All the rats were later presented the CS while licking a drinking tube for water, and CS-elicited suppression of licking was taken as an index of excitatory conditioning. The magnitude of this suppression was found to increase as a function of US intensity.
\end{abstract}

Investigations of classical conditioning have indicated that backward pairings of conditioned stimuli (CSs) and unconditioned stimuli (USs) produce a variety of results. Champion and Jones (1961), Matsumiya (1960), and Mowrer and Aiken (1954) discovered that backward presentations of CSs and USs endowed the CS with "excitatory" tendencies. In direct opposition to this evidence, Maier, Rapaport, and Wheatley (1976), Moscovitch (1972), Moscovitch and LoLordo (1968), Pavlov (1928), Plotkin and Oakley (1975), and Siegel and Domjan (1971, Experiment 1; 1974, conditioned suppression experiment) reported that backward CSs acquire "inhibitory" properties. Still other investigators (Bernstein, 1934; Harris, 1941; Spooner \& Kellogg, 1947) have contended that nonassociative factors such as pseudoconditioning or sensitization are responsible for the initial responding to the backward CS.

Recently, a number of studies (Heth, 1976; Heth \& Rescorla, 1973; Mahoney \& Ayres, 1976) have demonstrated reliable excitatory effects in a backward fear conditioning paradigm. Although the differences between backward and control groups in each of these studies were significant, the levels of conditioning obtained in the one-trial backward conditioning procedure by Mahoney and Ayres (1976) were extremely small, and no replication of their results has since been reported. The one-trial backward conditioning procedure is particularly interesting because it eliminates the possibility that any excitatory effects observed could be due to remote forward associations. It also would appear to minimize the possibility that any obtained results might be complicated by the learning of "autocontingencies" (Davis, Memmott, \& Hurwitz, 1975).

This research was presented at the 50th annual meeting of the Midwestern Psychological Association, Chicago, Illinois, May 5, 1978. The author gratefully acknowledges the helpful comments of John J. B. Ayres throughout this study. Requests for reprints should be addressed to Paul E. Burkhardt, Department of Psychiatry, University of Iowa Hospitals and Clinics, 500 Newton Road, Iowa City, Iowa 52242.
The purpose of the present investigation was, first, to attempt to replicate the effects reported by Mahoney and Ayres and, second, to increase the magnitude of their effects by using higher shock intensities.

Beritov (1965) has examined the properties of US intensity in a backward conditioning paradigm. His observations revealed that responding was inversely related to the US such that the strongest evidence of backward conditioning was obtained when a relatively weak US was employed. To explain these results, Beritov proposed a US-produced cortical inhibition mechanism that blocked the transmission of impulses from the CS to the US cortical sites. The amount of inhibition produced was a direct function of US intensity. Based on this theory, the use of higher shock intensities in the present study would decrease, rather than increase, the effects of backward conditioning shown by Mahoney and Ayres (1976).

There are, however, several theoretical positions that predict that higher shock intensities should yield more excitatory conditioning in a backward paradigm. According to Cautela (1965), backward conditioning reflects a forward pairing of the CS with the perceived pain of an aversive US. This perception of pain would be more acute under higher intensities of shock, and, therefore, the CS should become more excitatory.

Another theory, proposed by Terry and Wagner (1975), also predicts greater conditioning in a backward paradigm when higher shock intensities are used. Terry and Wagner hypothesize that the CS-US association depends upon the posttrial rehearsal of these events in short-term memory. This rehearsal is more likely to be initiated when surprising events occur during the course of training. Shocks of higher intensity should be more surprising than those of lower intensity and, hence, more likely to be rehearsed along with events with which they are temporally contiguous, including backward CSs.

Finally, Mowrer and Aiken (1954) view excitatory backward conditioning as a product of a second-order 
conditioning process. Initially, the apparatus cues become excitatory through the presentation of the US. The CS then acquires conditioned strength by preceding, or occurring simultaneously with, the excitatory apparatus cues. According to this theory, the apparatus cues, and thus the backward CS, should control greater excitation when a US of higher intensity is employed.

\section{METHOD}

\section{Subjects}

Thirty-five male Sprague-Dawley rats, approximately 100110 days old, were obtained from Harlan Industries, Madison, Wisconsin. The animals were watered and fed freely for 1 week before the start of deprivation.

\section{Apparatus}

The apparatus was one Grason-Stadler Model E conditioning chamber housed in a $.56-\mathrm{m}$ cube of $2.5-\mathrm{mm}$ metal. The chamber was lit by a $28-\mathrm{V}$ cue light located on one wall $14.5 \mathrm{~cm}$ above the floor and $14.5 \mathrm{~cm}$ from an adjacent wall. On one wall of the conditioning chamber was a $2 \times 2 \mathrm{~cm}$ hole through which a drinking tube was placed. The tube was attached to a bottle of tap water and to a drinkometer that recorded licks. The CS was an $80-\mathrm{dB}$ white noise (re: $20 \mu \mathrm{N} / \mathrm{m}^{2}$ ) produced by a Wavetek Digital VCG Model 133 noise generator and presented through a $10-\mathrm{cm}$ speaker mounted on the ceiling of the chamber. The US was a scrambled grid shock provided by a Grason-Stadler Model E1064GS shock source. Events in the experimental chamber were controlled and recorded by programming equipment located in an adjacent room.

\section{Procedure}

All rats were water deprived $23.5 \mathrm{~h}$ prior to Day 1 of preliminary training. Throughout the rest of the experiment, they were allowed access to water for $.5 \mathrm{~h}$ following each daily session.

Preliminary training. In the first 4 days of training, each rat was allowed to make 110 licks on the drinking tube. The dependent measures recorded included the latency to the first lick, time between Licks 1 and 90, time between Licks 90 and 100, and time between Licks 100 and 110 .

Conditioning. On Day 5, the water bottle was removed from the conditioning chamber, and four groups of rats $(n=7)$ each received one presentation of a 4-sec $80-\mathrm{dB}$ white-noise CS starting simultaneously with the termination of a 4-sec grid shock US of .5, 1.0, 1.6, and $2.0 \mathrm{~mA}$. These groups were labeled Groups .5, 1.0, 1.6, and 2.0, respectively. The control, Group C, received a single 4-sec 2.0-mA grid shock US. The US was turned on $150 \mathrm{sec}$ after each rat was placed in the conditioning chamber; the duration of each session was $432 \mathrm{sec}$.

Test for conditioning. Days 6 and 7 were tests for conditioning. The procedure used here was identical to preliminary training except that the noise CS was turned on after 100 licks and remained on until 10 additional licks had occurred. Dependent measures recorded included the latency to the first lick, time between Licks 1 and 90, time between Licks 90 and 100, and time between Licks 100 and 110. The last three measures were defined as the recovery time, pre-CS time, and CS time, respectively. The CS time was taken as an index of excitation conditioned to the CS.

\section{RESULTS}

Of the four dependent measures recorded in this experiment, the CS time was most relevant to the main prediction that CS-elicited suppression of licking should increase with shock intensity. The results tend to support this hypothesis.
Table 1

Median CS Times in Seconds on Test Days 1 and 2 and

Dummy CS Times for the Last Lick-Training Session

\begin{tabular}{cccc}
\hline Group & $\begin{array}{c}\text { Last Train- } \\
\text { ing Session }\end{array}$ & $\begin{array}{c}\text { Test } \\
\text { Day 1 }\end{array}$ & $\begin{array}{c}\text { Test } \\
\text { Day 2 }\end{array}$ \\
\hline C & 1.3 & 2.7 & 1.9 \\
.5 & 1.2 & 2.9 & 2.8 \\
1.0 & 1.3 & 48.8 & 24.3 \\
1.6 & 1.2 & 53.9 & 45.0 \\
2.0 & 1.3 & 84.5 & 32.7 \\
\hline
\end{tabular}

Note $-N=7$.

Table 1 depicts median CS times for each of the groups on the 2 test days and dummy CS times on the last lick-training day. A Kruskal-Wallis analysis of variance indicated that the groups did not differ in terms of CS times during the last lick-training day $(\mathrm{H}=3.2$, $\mathrm{p}>.5)$. However, inspection of CS times on Test Day 1 revealed that group differences were significant $(\mathrm{H}=$ $29.62, \mathrm{p}<.01)$. Planned comparisons using two-tailed Wilcoxon rank sums tests (Wilcoxon \& Wilcox, 1964) demonstrated that Groups 1.0, 1.6, and 2.0 suppressed significantly more than both Groups $\mathrm{C}$ and .5 (Ts = $77, \mathrm{p}<.01)$. In addition, a Jonckheere's test against an ordered alternative (Hollander \& Wolfe, 1973, pp. 120. 123) found the following rank order of groups to be highly reliable: $\mathrm{C}, .5,1.0,1.6$, and $2.0\left(\mathrm{~J}^{*}=5.81\right.$, $\mathrm{p}<.0002$ ). Further two-tailed Wilcoxon rank sums tests obtained significant differences between the following adjacent groups: .5 and $1.0(\mathrm{~T}=77, \mathrm{p}<.01)$, and 1.0 and $1.6(\mathrm{~T}=69, \mathrm{p}<.05)$.

On Test Day 2, significant differences were again observed $(\mathrm{H}=22.40, \mathrm{p}<.01)$. Planned Wilcoxon rank sums tests showed that Groups 1.0, 1.6, and 2.0 differed significantly from Group C (Ts $\geqslant 72, \mathrm{p}<.03)$. It was also determined that Groups 1.6 and 2.0 differed from Group $.5(\mathrm{Ts}=77, \mathrm{p}<.01)$.

An examination of the remaining dependent measures revealed no reliable differences among groups on the last lick-training day, Test Day 1, or Test Day 2.

\section{DISCUSSION}

The results of the present investigation replicated, in part, the excitatory effects of one-trial backward fear conditioning reported by Mahoney and Ayres (1976). The significant differences observed between the control, Group C, and Group 1.0 support their findings. In fact, more pronounced differences were obtained between backward and control groups in the present study. While more excitatory backward conditioning was found in this experiment than in that of Mahoney and Ayres, such variations between studies is presumably due to differences in equipment, rats, and the time of the year (see Kamin, 1965, for a discussion of these variables).

In addition to replicating the findings of Mahoney and Ayres (1976), the present results clearly demonstrate that the US intensity is an important determinant of conditioning in a backward conditioning paradigm. The magnitude of suppression was found to be directly related to the strength of the US. Groups receiving higher intensities of shock showed more suppression to the test CS than did those receiving lower intensities. This monotonic relationship between group suppression 
and US intensity was evident from inspection of median CS times in Table 1.

The clear effects of shock intensity on one-trial backward conditioning in the present study contrast with those described by Beritov (1965). In his examination of both forward and backward conditioning procedures, Beritov found that responding in a forward paradigm was directly related to the US intensity, whereas responding in a backward paradigm was inversely related to the US intensity. Since the manipulation of US intensity in these two procedures had different behavioral effects according to Beritov's general observations, he concluded that forward and backward conditioning developed independently and obeyed functionally different laws. The distinction between these two conditioning procedures was necessary for Pavlovian theorists to formulate a uniprocess account of both classical and instrumental conditioning. This theory was proposed to explain instrumental conditioning in terms of Pavlovian principles and became known as the bidirectional conditioning hypothesis (see Gormezano \& Tait, 1975).

The results of the present study do not support the hypothesis that forward and backward conditioning processes have different behavioral effects. Instead, the evidence presented here indicates that the two procedures may reflect similar processes. Theorists who predict the existence of excitatory backward conditioning (e.g., Cautela, 1965; Mowrer \& Aiken, 1954; Terry \& Wagner, 1975) appear to agree with the viewpoint presented in this study.

An important aspect of the present experiment was the utilization of a US-alone control procedure, which provided a conservative baseline to evaluate conditioning. For this control group, the test CS was novel and therefore should have produced some unconditioned suppression (see Domjan \& Siegel, 1971). The selection of the most intense US, $2.0 \mathrm{~mA}$, in this study was designed to maximize sensitization by the US. The small amount of sensitization observed in the control group, Group C, serves to strengthen the conclusion that the excitatory effects found in the remaining groups were indeed due to associative rather than nonassociative processes. (See Mahoney \& Ayres, 1976, p. 360, for a discussion of the baseline provided by the US-alone and explicitly unpaired controls and a comparison of their effects.)

The present evidence that a backward conditioning procedure can produce reliable excitatory conditioning is in agreement with a number of empirical and theoretical articles (Cautela, 1965; Champion \& Jones, 1961; Heth, 1976; Heth \& Rescorla, 1973; Mahoney \& Ayres, 1976; Matsumiya, 1960; Mowrer \& Aiken, 1954; Terry \& Wagner, 1975). Moreover, this investigation has demonstrated that the US intensity parameter is a critical determinant of such conditioning.

\section{REFERENCES}

BERITOV, I. S. [Neural mechanisms of higher vertebrate behavior] (W. T. Liberson, trans.). Boston: Little, Brown, 1965.

Bernstein, A. L. Temporal factors in the formation of conditioned eyelid reaction in human subjects. Journal of General Psychology, 1934, 10, 173-197.

Cautela, J. R. The problem of backward conditioning. Journal of Psychology, 1965, 60, 135-144.

Champion, R. A., \& Jones, J. E. Forward, backward, and pseudoconditioning of the GSR. Journal of Experimental Psychology, 1961, 62, 58-61.

Davis, H., Memmotт, J., \& Hurwitz, H. M. B. Autocon- tingencies: A model for subtle behavioral control. Journal of Experimental Psychology: General, 1975, 104, 169-188.

DomJan, M., \& SiEgEL, S. Conditioned suppression following CS preexposure. Psychonomic Science, 1971, 25, 11-12.

Gormezano, I., \& TAIt, R. W. The Pavlovian analysis of instrumental conditioning. Pavlovian Journal of Biological Sciences, 1976, 11, 37-55.

HarRis, J. D. Forward conditioning, backward conditioning, pseudoconditioning, and adaptation to the conditioned stimulus. Journal of Experimental Psychology, 1941, 28, 491-502.

Heтн, C. D. Simultaneous and backward fear conditioning as a function of number of CS-UCS pairings. Journal of Experimental Psychology: Animal Behavior Processes, 1976, 2, 117-129.

Heth, C. D., \& Rescorla, R. A. Simultaneous and backward fear conditioning in the rat. Journal of Comparative and Physiological Psychology, 1973, 82, 434-443.

Hollander, M., \& Wolfe, D. A. Nonparametric statistical methods. New York: Wiley, 1973.

KAMIN, L. J. Temporal and intensity characteristics of the conditioned stimulus. In W. F. Prokasy (Ed.), Classical conditioning. New York: Appleton-Century-Crofts, 1965.

Mahoney, W. J., \& Ayres, J. J. B. One-trial simultaneous and backward fear conditioning as reflected in conditioned suppression of licking in rats. Animal Learning \& Behavior, 1976, 4, 357-362.

Maier, S. F., Rapaport, P., \& Wheatley, K. L. Conditioned inhibition and the UCS-CS interval. Animal Learning \& Behavior, 1976, 4, 217-220.

Matsumiya, Y. The effects of US intensity and CS-US pattern on conditioned emotional response. Japanese Psychological Research, 1960, 2, 35-42.

Moscovitch, A. B. Pavlovian cessation conditioning. (Doctoral dissertation, University of Pennsylvania, 1972). Dissertation Abstracts International, 1972, 33, 1823B-1824B. (University Microfilms No. 72-25, 635)

Moscovitch, A. B., \& LoLondo, V. M. Role of safety in the Pavlovian backward fear conditioning procedure. Journal of Comparative and Physiological Psychology, 1968, 66, 673-678.

Mowrer, O. H., \& Aiken, E. G. Contiguity vs. drive-reduction in conditioned fear: Temporal variations in the conditioned and unconditioned stimulus. American Journal of Psychology, 1954, 67, 26-38.

Pavlov, I. P. Lectures on conditioned reflexes. New York: International Publishers, 1928.

Plotkin, H. C., \& OAKLey, D. A. Backward conditioning in the rabbit (Oryctolagus cuniculus). Journal of Comparative and Physiological Psychology, 1975, 88, 586-590.

Siegel, S., \& DomJan, M. Backward conditioning as an inhibitory procedure. Learning and Motivation, 1971, 2, 1-11.

SiEgel, S., \& Domjan, M. The inhibitory effect of backward conditioning as a function of the number of backward pairings. Bulletin of the Psychonomic Society, 1974, 4, 122-124.

Spooner, A., \& KellogG, W. N. The backward conditioning curve. American Journal of Psychology, 1947, 60, 321-334.

Terry, W. S., \& Wagner, A. R. Short-term memory for "surprising" versus "expected" unconditioned stimuli in Pavlovian conditioning. Journal of Experimental Psychology: Animal Behavior Processes, 1975, 104, 122-133.

Wilcoxon, F., \& Wilcox, R. Some rapid approximate statistical procedures. Pearl River, New York: Lederle Laboratories, 1964.

(Received for publication October 22, 1979.) 